\title{
AnI open Acquiring credentials in bedside
ultrasound: a cross-sectional survey
}

\author{
Resa E Lewiss, ${ }^{1}$ Turandot Saul, ${ }^{1}$ Marina Del Rios ${ }^{2}$
}

To cite: Lewiss RE, Saul T, Del Rios M. Acquiring credentials in bedside ultrasound: a cross-sectional survey. BMJ Open 2013;3: e003502. doi:10.1136/ bmjopen-2013-003502

- Prepublication history for this paper is available online. To view these files please visit the journal online (http://dx.doi.org/10.1136/ bmjopen-2013-003502).

Received 29 June 2013 Revised 24 July 2013 Accepted 26 July 2013

\footnotetext{
${ }^{1}$ Emergency Ultrasound Division, Department of Emergency Medicine, St Luke's-Roosevelt Hospital Center, New York, New York, USA

${ }^{2}$ Department of Emergency Medicine, University of Illinois at Chicago, Chicago, Illinois, USA
}

Correspondence to Dr Turandot Saul; tsaul@chpnet.org

\section{ABSTRACT}

Objective: Although there are training guidelines to credential emergency physicians in bedside ultrasound, many faculty groups have members who completed residency without a mandatory curriculum. These physicians are therefore required to learn bedside ultrasound while out in practice. The objective of this descriptive report is to illustrate a single academic facility's experience with acquiring credentials for emergency physicians in bedside ultrasound and the faculty's impressions on the motivators of and barriers to completion of the requirements.

Design: Cross-sectional survey.

Setting: Two urban teaching hospitals with a combined volume of 170000 visits a year.

Participants: 41 emergency medicine attending physicians.

Intervention: Emergency medicine attending physicians underwent training and credentialing in the applications of aorta and pelvic ultrasound over a 9-month period.

Outcome measure: After the credentialing period, we conducted a survey to evaluate the physicians' perceptions of this process.

Results: There were 41 faculty members during the credentialing survey period. 11 of the faculty members were exempt from ultrasound training. We asked attending physicians ( $\mathrm{N}=41$ exempt and non-exempt) to complete a web-based survey after the completion of the credentialing period. Questions about the potential barriers and incentives were listed and responders were asked to rank answers on a five-point Likert scale. Of the 31 respondents, $21(67.7 \%)$ completed the credentialing requirements by the 9 -month deadline. 19 of 26 emergency medicine residency trained physicians completed the requirements compared with $2 / 5$ of those that were not emergency medicine residency trained. Our pilot study data suggest an association between fewer years in practice and completion of the requirements.

Conclusions: This is a report on a single academic institution's experience with a faculty credentialing programme in bedside ultrasound for physicians with a diversity of prior experience in bedside ultrasonography. We describe the success of the credentialing process and identify survey-based faculty characteristics associated with fulfilling the requirements.

\section{INTRODUCTION}

At present, there is a well-delineated history of the development for emergency medicine (EM) resident training guidelines for bedside

\section{ARTICLE SUMMARY}

\section{Article focus}

- To describe a single academic facility's experience with a faculty credentialing process in bedside ultrasound.

- To discuss the faculty's impressions on motivators to completion of the bedside ultrasound requirements.

- To discuss the faculty's impressions on barriers to completion of the bedside ultrasound requirements.

\section{Key messages}

- A faculty credentialing programme in bedside ultrasound should have clearly defined goals supported by the emergency medicine departmental leadership.

- Protected time outside clinical duties dedicated to self-directed education is a motivator to the bedside ultrasound credentialing process.

- Opportunities for direct supervision of bedside ultrasound technique and mentoring enhance the credentialing process.

Strengths and limitations of this study

- The hospital where this credentialing programme in bedside ultrasound was instituted included physicians with diverse prior experience in bedside ultrasonography. This descriptive report for an academic institution may not reflect that of private and community physician groups in non-academic settings starting a credentialing programme for ultrasound.

ultrasound (BUS). In 1994, Mateer et al set forth recommendations for an ultrasound curriculum in residency training programmes. This discussion has evolved and in 2001 the American College of Emergency Physicians (ACEP) published the Emergency Ultrasound Guidelines which outlined the recommendations for adequate documentation, quality assurance programmes, credentialing and continuing medical education. ${ }^{2}$ More recently, the 2008 ACEP guidelines and the 2009 Core (Level 1) Ultrasound Curriculum from the College of Emergency Medicine in London, UK set forth more comprehensive statements which expanded core applications and specifications for US training. ${ }^{34}$ 
In 2012, the Accreditation Council for Graduate Medical Education (ACGME) designated ultrasound as 1 of 23 milestone competencies for EM residency graduates. ${ }^{5}$ With the increasing scrutiny of medical educational programmes and their effects on patient safety and healthcare delivery, standardised ultrasound training and competency assessment are imperative. In contrast, BUS education and credentialing in community and academic emergency departments (EDs) where practicing physicians did not receive training remains a challenge. Moore et at reported in their survey results of community EDs that lack of training of emergency physicians is the largest barrier to implementation of BUS.

The Core (Level 1) Curriculum by the College of Emergency Medicine, UK presents guidelines for trainees and the ACEP policy statement presents a practice pathway that gives meaningful recommendations for credentialing EM attending physicians in BUS who completed residency before established emergency ultrasound residency training curricula. ${ }^{2} 4$ Training in BUS is particularly unique in that it requires both the hands-on skill of scanning combined with the cognitive skill of recognising anatomy and pathological processes and interpreting images. ${ }^{7}$ Comprehending the barriers and incentives to BUS training and credentialing as perceived by practicing emergency physicians may aid in the development of a more successful credentialing standard.

This paper describes our institution's experience with faculty training in BUS. Numerous publications address medical student and resident BUS curricula, training and experiences with the process. ${ }^{8-10}$ This survey addressed faculty opinions of BUS and the perceptions of the faculty members required to complete the process of acquiring credentials in ultrasound. After completion of our institution's credentialing process for the applications of aorta and pelvic ultrasound, we conducted a survey to evaluate our faculty member's prior experience and training in BUS and their perceptions of the credentialing procedure.

\section{METHODS}

St. Luke's-Roosevelt (SLR) Hospital Center is comprised of two separate urban teaching hospitals with a combined volume of 170000 visits a year. In 2008, attending physicians without training in BUS attended a $16 \mathrm{~h}$ training course upon joining the SLR Hospital Center faculty. The credentialing process was as follows: for each BUS application, the faculty were asked to submit 25 technically adequate ultrasound scans of which a certain number were positive studies (in the case of aorta, at least 2-3 abdominal aneurysms and for pelvic ultrasound, at least 12 intrauterine gestations). Each faculty member then completed a written examination comprising multiple choice and image identification questions pertaining to the respective BUS application.
Subsequently, one of the ultrasound division faculty members reviewed the examination with the faculty member and oversaw a hands-on competency examination with bedside real-time scanning of a volunteer patient or model. With successful completion of the delineated steps, a credentialing letter specific to that application was sent to the department chairperson and the hospital credentialing committee for emergency procedures. On completion, the physician was considered 'credentialed' and permitted to make clinical decisions based on their BUS examinations and interpretations.

There were a total of 41 faculty members during the credentialing and survey period, from January 2009 to September 2009. Eleven of the faculty members were considered exempt: those who were credentialed while faculty members at our institution by completion of the requirements we described above prior to our survey, those who received ultrasound training during their EM residency training at SLR Hospital Center and the physician who worked solely as an urgent care (fast track) provider.

Under the direction of the chairman and BUS director, all non-exempt adult EM faculty members were required to acquire credentials in aortic and pelvic ultrasound. These applications were chosen due to the immediacy of these ultrasound examination interpretations in patient care decision-making. Paediatric emergency physicians were asked to complete the credentialing requirements in pelvic ultrasound only. Faculty members were given 9 months to complete the requirements for acquiring credentials in these two applications.

We asked all 41 of our attending physicians (exempt and non-exempt) to complete a web-based survey at the end of the 9-month period. The purpose of the survey was to assess their prior experience with BUS and their opinions of the faculty credentialing process. Questions focused on barriers and incentives to acquiring credentials, and responders were asked to rank answers on a five-point Likert scale (where one was most important and five was least important). The survey included an open-ended question where responders were asked to give suggestions on how to improve the programme. Institutional Review Board approval was obtained for the web-based survey and no participant identifying data were collected. Descriptive statistics, frequencies and crosstab analyses were performed using $\mathrm{R}$ Project for Statistical Computing.

\section{RESULTS}

In total, 31 of 41 faculty members participated. The majority of respondents (26/31) were residency trained in EM. The remaining five respondents trained in other specialties and had not received dedicated ultrasound training prior to arriving to our institution. When asked how interested they were in BUS (table 1), most of our faculty members responded positively with $27 / 31$ (87\%) indicating that they use ultrasound 'at least sometimes'. 
Table 1 Faculty interest in bedside ultrasound

\begin{tabular}{ll}
\hline How interested would you say you are in & \\
bedside ultrasound? & $\mathbf{N = 3 1}$ \\
\hline I use it all the time & 13 \\
Sometimes, if there might be an interesting finding & 14 \\
Only when I have to, during off hours & 2 \\
Leave this to the radiologists & 1 \\
No answer & 1 \\
\hline
\end{tabular}

Of the 31 respondents, $21(67.7 \%)$ reported completion of our institution's credentialing requirements in the 9-month period, $3(9.6 \%)$ did not specify and 7 $(22.6 \%)$ did not complete the requirements. Characteristics that may be associated with the completion of the credentialing requirements are summarised in table 2. Residency training in EM and formal training in BUS during residency were correlated with successful completion of the programme: 19/26 EM residency trained physicians completed the requirements compared with $2 / 5$ of those that were not EM residency trained. The mean postgraduate year (a surrogate measure for average number of years in practice) was higher in the group that did not complete the credentialing requirements. Seniority within our EM faculty had no impact on successful completion of the credentialing process with the average number of years in practice at SLR Hospital Center being similar among the two groups (8.8 vs 9.1).

The faculty who successfully fulfilled the requirements for acquiring credentials in BUS graded the importance they placed on certain motivators to completion: concern for disciplinary action by the chairman (10/ 21), increasing clinical competence to improve patient care $(11 / 21)$ and improving the ability to disposition patients faster $(10 / 21)$ were among the most important motivators identified. Personal interest and resident education were important motivators for only $28 \%(6 / 21)$.

The seven physicians who did not complete the requirements answered questions on barriers faced during the credentialing process (table 3). Too many other demands on their time $(5 / 7)$ was a more
Table 3 Barriers for those who did not complete requirements

\begin{tabular}{ll}
\hline Barrier to completion & $\mathrm{N}=7$ \\
\hline Could not get the scan numbers & 3 \\
Amount of work outweighed the benefits & 2 \\
Too many other demands on time & 5 \\
Did not know how to ultrasound and not enough & 2 \\
education & \\
Did not know about the programme & 0 \\
\hline
\end{tabular}

important barrier than lack of knowledge in ultrasound $(2 / 7)$. The steps towards the credentialing process appeared to be burdensome to some of our faculty, with $2 / 7$ ranking the amount of work entailed in acquiring credentials outweighing the benefits and $3 / 7$ ranking obtaining the required number of scans as important barriers. None of the survey respondents indicated that unawareness of the requirements was a barrier.

Respondents who did not complete the credentialing requirements were asked to rank the above barriers on a five-point Likert scale, with one being most important and five least important. The numbers in this table represent the responders who ranked a given barrier as 1 or 2 .

We asked all our respondents to grade the overall obstacles towards completion of the requirements (table 4). The majority of survey respondents $(20 / 31)$ indicated that clinical shifts were too busy to complete the credentialing requirements. The number of scans required for credentialing was viewed as an important obstacle for a large minority $(10 / 31)$ of our faculty. Having ultrasound services from the radiology department available for patient referrals from the $\mathrm{ED}$ was also viewed as a barrier to obtaining the number of required scans (10/31). A smaller, although not negligible, number ranked medicolegal risks of incorrect interpretation as a deterrence to completing the credentialing programme $(8 / 31)$.

For the purposes of increasing the ease and efficiency of the credentialing process, the faculty were encouraged to offer subjective comments. Only two faculty members stated that there was no need for a change in

Table 2 Potential predictors of credentialing programme completion

\begin{tabular}{|c|c|c|c|c|}
\hline & $\begin{array}{l}\text { Requirements completed } \\
(\mathrm{N}=21) \text {, mean (median, range) }\end{array}$ & $\begin{array}{l}\text { Requirements not completed } \\
(\mathrm{N}=7) \text {, mean (median, range) }\end{array}$ & $\begin{array}{l}\text { Did not } \\
\text { specify }\end{array}$ & Totals \\
\hline EM residency trained & 19 & 4 & 3 & 26 \\
\hline $\begin{array}{l}\text { Non-EM residency } \\
\text { trained }\end{array}$ & 2 & 3 & 0 & 5 \\
\hline $\begin{array}{l}\text { US curriculum in } \\
\text { residency }\end{array}$ & 6 & 0 & 0 & 6 \\
\hline PGY & $9(8,7-12)$ & $15(15,8-21)$ & & \\
\hline $\begin{array}{l}\text { Years of practice at } \\
\text { SLR }\end{array}$ & $8.8(7,(6.2-11.5)$ & $9.1(7,3.0-15.3)$ & & \\
\hline
\end{tabular}




\section{Table 4 Overall obstacles to acquiring credentials}

\begin{tabular}{lc}
\hline Obstacle & $\mathbf{N}=\mathbf{3 1}$ \\
\hline Too many scans required & 10 \\
Too many true positives required & 10 \\
Medicolegal risks of incorrect interpretation & 8 \\
Shifts are too busy & 20 \\
Radiology is readily available & 9 \\
\hline All survey respondents were asked to rank the above obstacles on \\
a five-point Likert scale, with 1 being most important and 5 least \\
important. The numbers in this table represent the total number of \\
responders who ranked a given obstacle as 1 or 2.
\end{tabular}

our programme for acquiring credentials. Another 15 faculty members offered their ideas. The two most important themes in the answers to this question were a need for more mentorship and time. The most common requests were more one-on-one and hands-on training sessions and more immediate feedback on performance. Several faculty members expressed concern over the time investment required to complete the steps towards acquiring credentials. Several of our faculty believed that clinical shifts were too busy, suggesting that time outside scheduled clinical duties would be required to complete the requirements.

\section{DISCUSSION}

We report a single academic institution's experience with a programme to acquire credentials in BUS for a faculty with varied prior experience with ultrasound. The insight gained from this pilot data is being incorporated into the design of a curriculum for faculty credentialing in BUS.

This descriptive report for an academic institution may not reflect that of private and community physician groups in non-academic settings starting a credentialing programme for emergency BUS. An important factor present in the academic setting is the presence of EM residents and their enthusiasm for learning new technologies. A second factor is the existence of an ultrasound fellowship with fellows and dedicated faculty. These are likely motivators for the more senior physicians who supervise the residents and work clinically with fellows.

Likewise, the barriers faced by the non-academic emergency physician may be different from those of attending physicians in academic centres. Specifically, a lack of knowledge in ultrasound was cited by only two of our physicians as an important barrier, perhaps because of the now routine exposure to the technology. We suspect that knowledge in ultrasound may be a more important barrier for the community physician who is without the benefit of regular educational opportunities such as lectures and conferences on ultrasound.

Despite the stated limitations, we believe that this paper can provide valuable insight to physicians interested in developing a credentialing programme for their faculty regardless of the setting (academic vs non-academic). A number of the respondents to our survey stated concerns about the need for more hands-on training and mentoring, suggesting that the truncated training experience may not be sufficient for experienced EM clinicians to feel they can perform and interpret scans independently. These concerns are most likely echoed by our colleagues in non-academic centres who may not have dedicated personnel for training and quality assurance. Some of the other barriers echoed by several of our faculty members, such as lack of time during clinical shifts to practice ultrasound and the need for more protected time in order to complete the requirements, are also likely to be experienced by the non-academic physician who has little or no compensated non-clinical time.

\section{CONCLUSION}

Based on the experience at our urban academic hospital centre and the web-based survey responses, we report a single academic institution's experience with a credentialing programme in BUS. The insight gained from these results may be incorporated into the design of a curriculum for acquiring credentials in BUS.

We consider the following questions as opportunities for future study:

- How can the curriculum for credentialing in BUS be modified to ensure the successful completion of the requirements?

- What motivators can be identified to increase successful completion of credentialing requirements?

- What is the best means of training the emergency physicians in practice who did not learn BUS during residency but who need to learn this due to patient safety standards.

Contributors REL was involved in study conception and design, drafting of the manuscript and general supervision of research. TS was involved in survey design, data acquisition and drafting of the manuscript. MDR was involved in survey design, statistical analysis, interpretation of data and drafting of the manuscript.

Funding This research received no specific grant from any funding agency in the public, commercial or not-for-profit sectors.

Competing interests None.

Ethics approval St Luke's Roosevelt Institutional Review Board.

Provenance and peer review Not commissioned; externally peer reviewed.

Data sharing statement No additional data are available.

Open Access This is an Open Access article distributed in accordance with the Creative Commons Attribution Non Commercial (CC BY-NC 3.0) license, which permits others to distribute, remix, adapt, build upon this work noncommercially, and license their derivative works on different terms, provided the original work is properly cited and the use is non-commercial. See: http:// creativecommons.org/licenses/by-nc/3.0/

\section{REFERENCES}

1. Mateer J. Model curriculum for physician training in emergency ultrasonography. Ann Emerg Med 1994;23:95-102.

2. American College of Emergency Physicians. ACEP emergency ultrasound guidelines-2001. Ann Emerg Med 2001;38:470-81.

3. ACEP Policy Statement. Emergency ultrasound guidelines. Ann Emerg Med 2009;53:550-70.

4. Sloan J. eds. Core (Level 1) Ultrasound Curriculum [Internet]. The College of Emergency Medicine. London, UK. http://www. collemergencymed.ac.uk/Training-Exams/Training/Ultrasound\% 20training/ (accessed Apr 2013). 
5. The Emergency Medicine Milestone Project [Internet]. 2012. http:// www.abem.org/PUBLIC/_Rainbow/Documents/

EMMilestonesMeeting4Final1092012.pdf (accessed Apr 2013).

6. Moore CL, Molina AA, Lin H. Ultrasonography in community emergency departments in the United States: access to ultrasonography performed by consultants and status of emergency physician-performed ultrasonography. Ann Emerg Med 2006;47:147-53.

7. Kendall JL, Hoffenberg SR, Smith RS. History of emergency and critical care ultrasound: the evolution of a new imaging paradigm. Crit Care Med 2007;35(5 Suppl):S126-30.
8. Jeppesen KM, Bahner DP. Teaching bedside sonography using peer mentoring. J Ultrasound Med 2012;31:455-9.

9. Damewood S, Jeanmonod D, Cadigan B. Comparison of a multimedia simulator to a human model for teaching FAST exam image interpretation and image acquisition. Acad Emerg Med 2011;18:413-19.

10. Platz E, Goldflam K, Mennicke M, et al. Comparison of web-versus classroom based basic ultrasonographic and EFAST training in 2 European hospitals. Ann Emerg Med 2010;56:660-9. 